\title{
Influence of the Subtle Energetic Changes on the Treatment Response in Patients with Insomnia
}

\author{
Edvard V. Kryzhanovskii ${ }^{1}$, Alexander B. Yavorsky ${ }^{2}$ \& Kwong C. Lim $^{3}$ \\ ${ }^{1}$ Telebiomet, SIE of Moscow Technical University of Communications and Informatics, Saint-Petersburg, Russia \\ ${ }^{2}$ Sports Medicine Clinics of Russian State University of Physical Education, Sport, Youth and Tourism, Moscow, \\ Russia \\ ${ }^{3}$ BAE International Inc.SDN BHD, Kuala-Lumpur, Malaysia \\ Correspondence: Kryzhanovskii Edvard, Telebiomet, SIE of Moscow Technical University of Communications \\ and Informatics, 18H, 12 Sveaborgskaia, Saint-Petersburg, Russia. Tel: 7-921-951-2674.
}

Received: May 26, 2017 Accepted: July 8, 2017 Online Published: July 14, 2017

doi:10.5539/gjhs.v9n9p90 URL: https://doi.org/10.5539/gjhs.v9n9p90

\begin{abstract}
The article examines the questions of the treatment of insomnia in patients who do not have neurological, mental, and somatic disorders. A nonmedicamental method of sleep disturbance correction in persons with psychophysiological insomnia is considered. In particular, it is proposed to use AM-therapy as a method of insomnia treatment which implies that the patients sleep on the special activated mattresses. To assess the condition of patients before and after the treatment, clinical, psychophysiological and electroencephalographic (EEG) methods are used. The effectiveness of applying this type of insomnia therapy is provided by the improvement of the psychological indicators and EEG data.
\end{abstract}

Keywords: insomnia, therapy, subtle energy

\section{Introduction}

Insomnia is one of the prevalent diseases in the world - from 28 to $45 \%$ of the world population suffer the symptoms of insomnia. Women are prone to insomnia 1.3 times more often than men. People over 65 years meet difficulties with sleeping 1.5 times more often than younger ones. People older than 60 years complain about poor quality of sleep 3-4 times more often than those of the average age. Sleeping pills (hypnotics) of nonprescription group are widely used for the treatment of insomnia. But uncontrolled constant usage of such pills causes significant secondary changes in sleep patterns and adversely affects the quality characteristics of the waking period (Doghramji, 2006; Morphy, Dunn, Lewis, Boardman, \& Croft, 2007; Meyer, 1998).

Quality of sleep is a component of quality of life. Often chronic sleep disorders lead to the use of nootropics, psychostimulants, antidepressants, antipsychotics, antihypertensives and antimalarial drugs, antibiotics, hormones, certain antiarrhythmic drugs and vitamins (vitamin $\mathrm{C}$ ).

The history of pharmacotherapy of sleep disorders has had several stages. Before the beginning of the XX century bromine and opium were used in the treatment of insomnia. In 1903, barbiturates started to be applied. In the early 1950s neuroleptics (mainly phenothiazine derivatives), and antihistamines began to be used. All of these drugs can be attributed to the first generation of sleeping pills, which usage as a hypnotic is currently extremely limited. With its advent in 1960, diazepam and oxazepam open the era of the benzodiazepine hypnotics' second generation (Schutte-Rodin, Broch, Buysse, Dorsey, \& Sateia, 2008; Walsh et al., 2000; Roehrs, Papineau, Rosenthal, \& Roth, 1999).

However, a group of benzodiazepines has brought certain problems into a clinical practice of insomnia: benzodiazepines cause addiction and require an increase of the daily dose; moreover, benzodiazepines lead to the increased manifestations of sleep apnea as a result of muscle relaxant.

The third generation of hypnotics includes the relatively new drugs developed in 1980-1990 years: derivatives of tsiklopirrolana - zopiclone (imovan) and derivatives of imidazopyridine - zolpidem (ivadal) which almost meet the requirements for the ideal sleeping pills. A new direction in the treatment of insomnia is the use of synthetic analogues of the hormone melatonin. Third generation hypnotics (zopiclone, zolpidem and zaleplon) and 
melatonin are rarely used as the expected clinical effect is not well known (Doghramji, 2006; Lie, Tu, Shen, \& Wong, 2015).

When the hypnotics are prescribed, the half-life of drugs should be taken into account. Hypnotics with a short half-life are most often used for the therapy of presomnical disorders among working people engaged in potentially hazardous activities. Drugs with long half-life are used only for the normalization of sleep in case of violation of its duration. Among the third generations of sleeping pills, barbiturates are of the greatest danger considering the risk of the toxic effects.

Potentially possible severity of barbiturate intoxication depends on the drug dose. Mild poisoning occurs when amount of barbiturates 3-4 times exceeds the therapeutic (hypnotics) dose. Poisoning of moderate and severe degree takes place when barbiturate dose exceeds therapeutic one by 5-10 times.

The development of acute poisoning by hypnotic drugs depends on the dose of the drug and its mechanism of action, combination with other agents, reinforcing effects of sleeping pills, as well as the individual reaction (Ringdahl, Pereira, \& Delzell, 2004; Kay-Stacey \& Attarian, 2016).

With an overdose of hypnotic drugs the polysynaptic brain structure is oppressed and weakens impulses which activate the reticular formation on the cerebral cortex. In large doses, barbiturates depress the respiratory and vasomotor centers.

Therefore, it is relevant to study a non-drug treatment of insomnia.

Previous work (Krizhanovsky \& Lim, 2014) shows the changes of healthy people state under the influence of specialized mattresses, with a basis of cotton eco-friendly materials of filler and cover exposed to activation (AM) in the area of natural energy fields.

This work is devoted to revealing the differences between the states of patients with psychophysiological insomnia using an ordinary mattress $(\mathrm{OM})$ with a basis of cotton eco-friendly materials of filler and cover and using the similar matresses but exposed to activation (AM, activated mattress) in the area of natural energy fields in Malaysia within 1 day, so called AM therapy (Figure 1). Activated mattress contains the optical memorable material received from a mix of the photoaddressed polymer and, at least, one additive. A certain ratio of the influences having various directions of polarization is written down in the optical memorable layer by means of the polarized light. Technical result is storage of favorable electromagnetic influence impact on a mattress and a resonance at useful frequencies for the person.

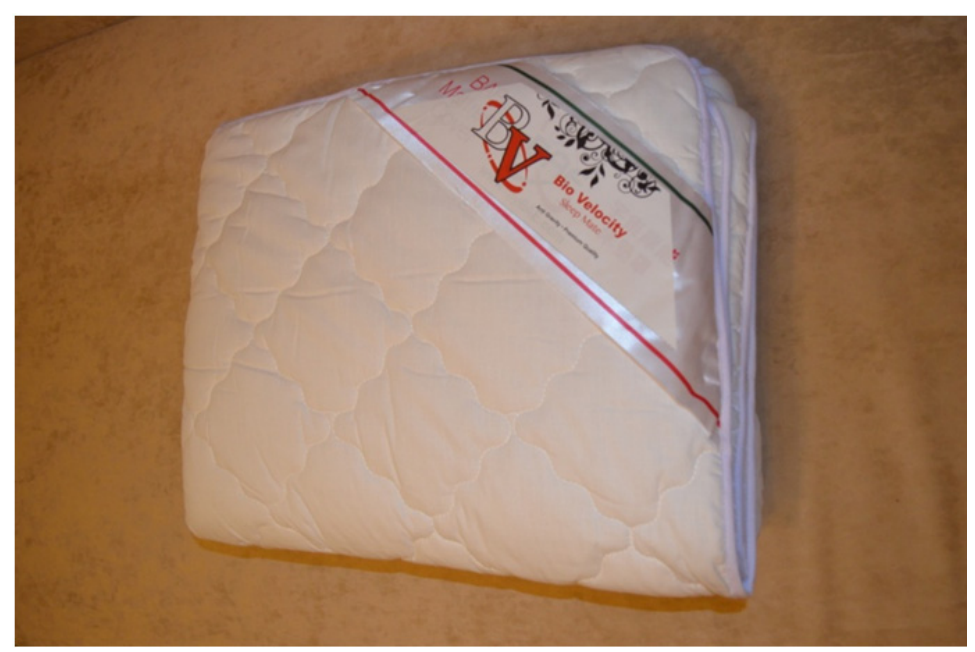

Figure.1. Activated mattress.

\section{Method}

The study was conducted on the basis of Sports Medicine Clinics of The Russian State University of Physical Education, Sport, Youth and Tourism in Moscow. Evaluation of the subjective state of clinical parameters is performed in 18 patients with psychophysiological insomnia without comorbidities.

In order to obtain the most reliable data, the following patient selection parameters are applied. The age of patients 
varies from 22 to 50 years with a mean age of 36 years. The criterion for exclusion from the study is the presence of arrhythmias, pacemakers, injuries and brain tumors, mental illness, thyrotoxicosis. Among the patients, women account for $61 \%(n=11)$ and men - for $39 \%(n=7)$.

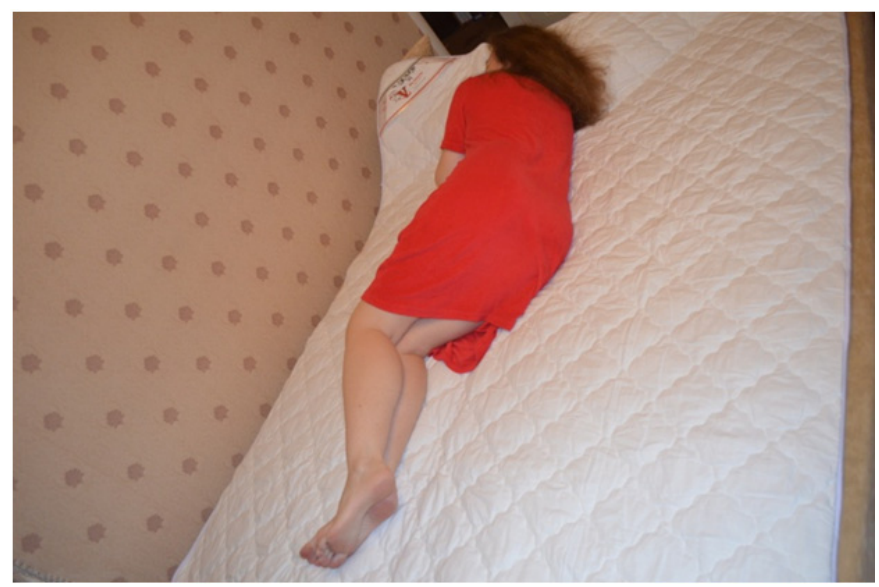

Figure 2. The process of patient sleeping on AM

All patients are volunteers and they are matched to the same type of sleep disorders - psychophysiological insomnia. All patients have signed the informed consent to participation in the research.

We divide patients into two groups with nine people in each one, so that patients of group 1 are truly informed that they are to be affected by the AM during their sleep and the patients of group 2 are wrongly informed that they are to be influenced by AM during their sleep (in fact they used placebo cover). The mattress is placed under the patient (Figure 2).

The analysis of human state is carried out with the help of polysomnography, blood pressure assessment, heart rate and psychological testing. EEG study is conducted on "Neurosoft" electroencephalograph, made in Russia, Ivanovo. The standard scheme of bipolar leads with 21 channels is applied. And the bridge type of electrodes is used.

Efficiency of the therapy is estimated by the means of clinical and psychometric methods of a research in 2 weeks influence.

All personal cards of patients are processed by the means of the descriptive and comparative statistics. The descriptive statistics are executed for all analyzable indices depending on the variable type. The analysis of the quantitative variables defines their arithmetic average, the minimum and maximum values, a standard deviation, and the analysis of qualitative variables - their frequency and part (as a percentage) in the total number.

Statistical analysis is carried out according to the distribution of sample by using of T-test and Fischer parametric criteria or Wilcoxon and Kolmogorov-Smirnov nonparametric test with the help of Statistica 10.0 software.

\section{Results}

The vast majority (76.5\%) of patients with insomnia associate it with the beginning of some traumatic situation (acute financial difficulties, problems at work or in the family and other circumstances).

Clinically registered sleep disorders are detected in all patients and, come to the fore in the clinical picture of a neurotic state.

The most frequent complaints are difficulties in falling asleep at night (72.4\%), frequent (more than 3-4 times per night) nocturnal awakenings (62.3\%), difficulties with morning awakening (41.6\%), daytime sleepiness (39.6 \%), lack of a sense of rest after a night's sleep (35.1\%), sudden nocturnal awakening with difficulties in falling asleep again $(28.3 \%)$. Statistically significant differences between the groups as well as gender-based pre-treatment differences are not revealed. Analysis of the relations between subjective measures of sleep patterns shows that the difficult morning awakening is associated with the duration of sleep $(p<0.05)$ and with the lack of sense of relaxation after sleep $(\mathrm{p}<0.05)$.

Surface sleep is significantly $(\mathrm{p}<0.05)$ correlated with the lack of sense of relaxation after sleep. Whereas, no 
statistically significant links are found between sleep duration and the feeling of cheerfulness in the morning. But there is a link between the lack of sleep and subjective sensations in the morning (lethargy, fatigue, irritability, headaches). The early final awakening is not accompanied by poor health state in the morning. Subjectively, patients in this group in most cases experience morning alertness and working capacity.

Based on the data, it can be stated that long-term falling asleep and difficulty in the morning awakening are associated with the feeling of lack of rest after sleep. On the contrary, the morning state of health is almost not connected with the middle insomnia.

After two weeks of therapy, we find a significant improvement in sleep quality according to the visual analog scale with the dynamics of the studied parameter in the Group 1 from 3.2 to 7.5 points, and in the Group 2 - from 3.1 to 3.6 points (Table. 1). Differences are not significant in the second group.

Table 1. Dynamics of the quality parameter of sleep on a visual analog scale of self-assessment.

\begin{tabular}{lll}
\hline \multirow{2}{*}{ Group } & \multicolumn{2}{l}{ Parameter, points } \\
\cline { 2 - 3 } & before treatment & after treatment \\
\hline 1-st & $3.2 \pm 0,23^{*}$ & $7.5 \pm 0,38^{*}$ \\
2-nd & $3.3 \pm 0,25$ & $3.6 \pm 0,22$ \\
\hline
\end{tabular}

* Significant differences between groups, $\mathrm{P}<0.05$.

We find that the use of AM significantly reduces the sensation of a lack of sleep when waking up and the presence of postsomnia disorders such as daytime sleepiness (Table 2, Figures 1 and 2).

Table 2. Dynamics of sleep quality parameters in the treatment process

\begin{tabular}{|c|c|c|c|c|}
\hline & \multicolumn{4}{|c|}{ Value of parameters, $\%$} \\
\hline & \multicolumn{2}{|l|}{ Group 1} & \multicolumn{2}{|l|}{ Group 2} \\
\hline & $\begin{array}{l}\text { before } \\
\text { treatment }\end{array}$ & $\begin{array}{l}\text { after } \\
\text { treatment }\end{array}$ & $\begin{array}{l}\text { before } \\
\text { treatment }\end{array}$ & $\begin{array}{l}\text { after } \\
\text { treatment }\end{array}$ \\
\hline $\begin{array}{l}\text { The inability to sleep for more than } 30 \\
\text { minutes }\end{array}$ & 70 & 20 & 72 & 69 \\
\hline $\begin{array}{l}\text { Falling asleep within 20-30 minutes after } \\
\text { bedtime }\end{array}$ & 3 & 22 & 3.8 & 4 \\
\hline Night waking up (3-4 per night) & 65 & 12 & 62 & 58 \\
\hline Sense of lack of sleep after a night & 45 & 10 & 46 & 42 \\
\hline Daytime sleepiness & 18 & 4,2 & 19 & 15 \\
\hline
\end{tabular}



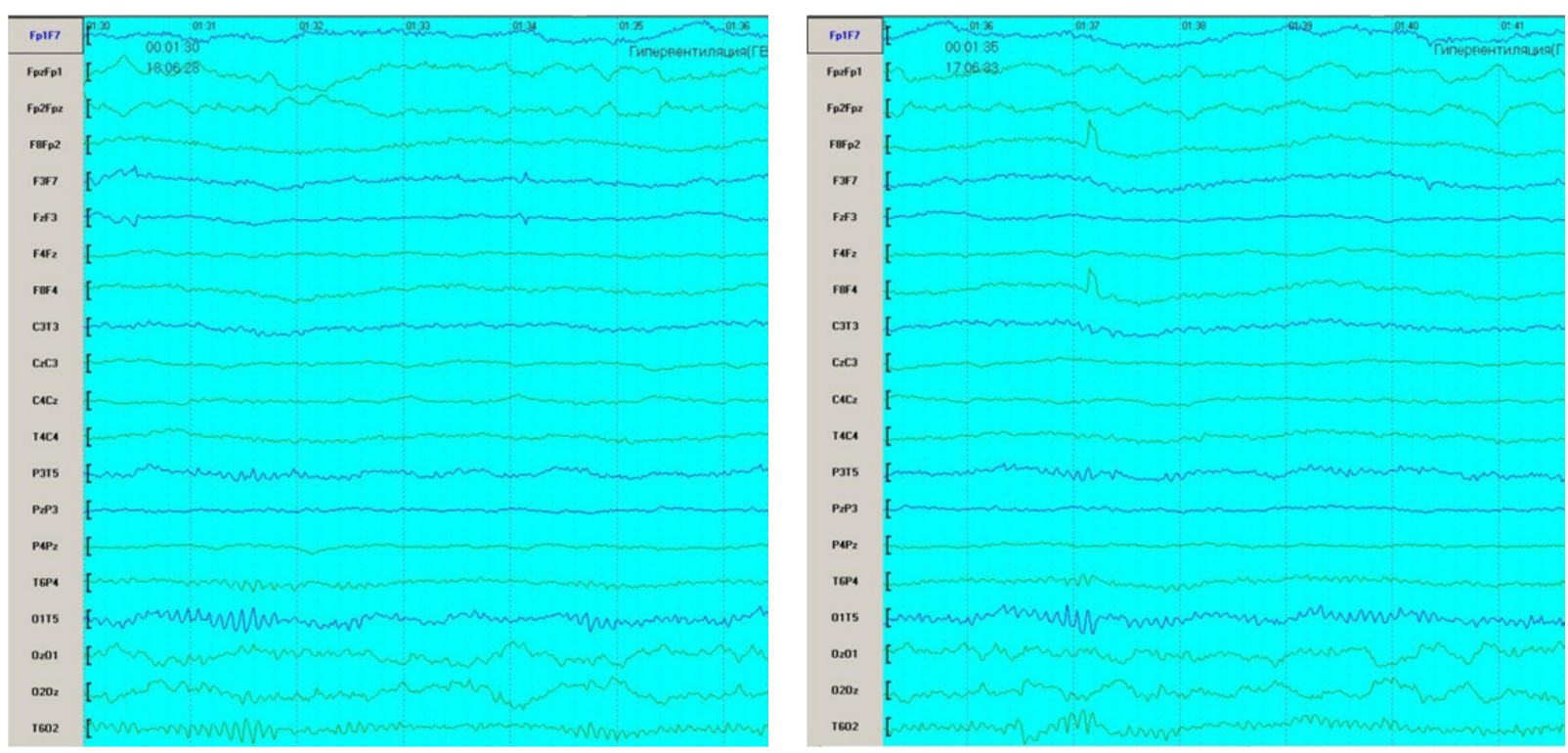

* Significant differences between groups, $\mathrm{P}<0.05$.

Figure 3. Patient P EEG data before and after two weeks of the study

A significant decrease is revealed in the level of reactive anxiety after AM-therapy in both groups. In the first group, after the treatment the average score on a Spielberger-Hanin scale of reactive anxiety is $36.2 \pm 1.78$ which is significantly lower than the respective value of $42.2 \pm 1.21$ before the treatment. And in the second group the values after and before the treatment are $39.8 \pm 1.88$ and $40.9 \pm 1.38$ accordingly. EEG changes in results are shown in the examples (Figures 3, 4).

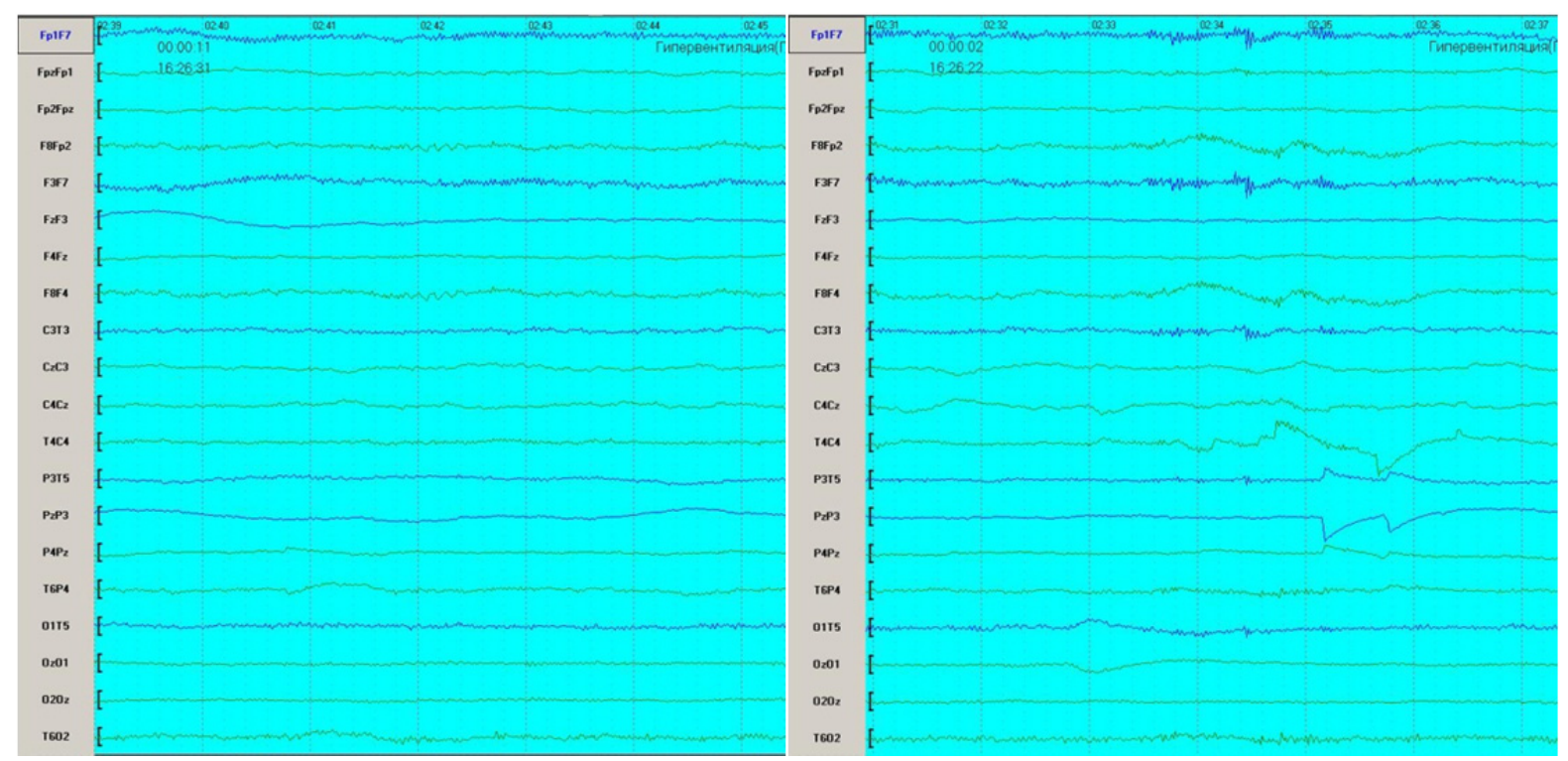

Figure 4. Patient O EEG data before and after two weeks of the study.

The process of the placement of sensors for measuring EEG is displayed in Figure 5. 


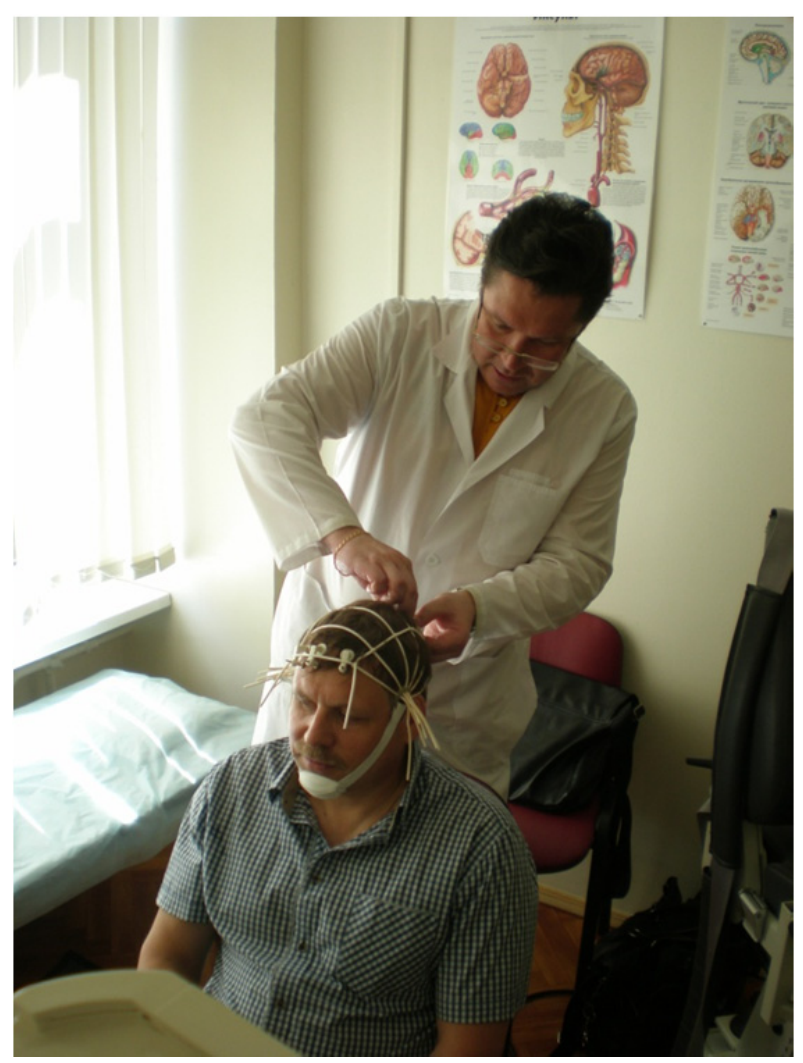

Figure 5. The process of EEG study

Compared with the initial data, a more clear response to the process of opening-closing of the eyes is observed on the EEG pattern after AM-therapy. There is a greater representation of the beta rhythm in the anterior (front) leads. These changes indicate a full-fledged functioning of the cerebral cortex.

\section{Discussion}

The dynamics of the individual qualitative and quantitative characteristics of sleep disorders in AM therapy tend to be positive for the Group 1. Whereas positive changes in the Group 2 are explained by the proper sleep hygiene in the clinic, as well as the placebo effect. Moreover, the changes in the second group are not significant.

AM-therapy acts positively against insomnia, it helps to reduce anxiety and to improve the state of mood. It is important to note that AM-therapy helps patients to fall asleep within 20-30 minutes. This is manifested by the EEG pattern, which also shows a clear reaction to the eyes opening-closing process. These changes in the EEG show full-fledged functioning of the cerebral cortex. Furthermore, the study reveals that AM therapy leads to the improvement of sleep quality and to the reduction of the number of nighttime awakenings and daytime sleepiness. AM therapy approach as a way of insomnia relief, together with the sleep hygiene, helps to effectively monitor the status of sleeping avoiding drug therapy which causes muscle relaxant and has a synaptic influence on patients with the same as in a given research symptoms of insomnia.

\section{Competing Interests Statement}

The authors declare that they has no competing or potential conflicts of interest.

\section{References}

Doghramji, K. (2006). The epidemiology and diagnosis of insomnia. Am J Manag Care, 12, 214-220.

Kay-Stacey, M., \& Attarian, H. (2016). Advances in the management of chronic insomnia. Bmj, 354, i2123. https://doi.org/10.1136/bmj.i2123

Krizhanovsky, E. V., \& Lim, K. C. (2014). Study of the Influence of Subtle Energetic Changes in Environment on the Productivity of the Process of Sleep. Open Journal of Ecology, 4(11), 693. https://doi.org/10.4236/oje.2014.411059

Lie, J. D., Tu, K. N., Shen, D. D., \& Wong, B. M. (2015). Pharmacological treatment of insomnia. Pharmacy and 
Therapeutics, 40(11), 759 .

Meyer, T. J. (1998). Evaluation and management of insomnia. Hosp Pract (Off Ed), 33, 75-78. https://doi.org/10.3810/hp.1998.12.122

Morphy, H., Dunn, K. M., Lewis, M., Boardman, H. F., \& Croft, P. R. (2007). Epidemiology of insomnia: a longitudinal study in a UK population. Sleep, 30, 274-80.

Ringdahl, E. N., Pereira, S. L., \& Delzell, J. E. (2004). Treatment of primary insomnia. The Journal of the American Board of Family Practice, 17(3), 212-219. https://doi.org/10.3122/jabfm.17.3.212

Roehrs, T., Papineau, K., Rosenthal, L., \& Roth, T. (1999). Ethanol as a hypnotic in insomniacs: Self administration and effects on sleep and mood. Neuropsychopharmacology, 20, 27-86. https://doi.org/10.1016/S0893-133X(98)00068-2

Schutte-Rodin, S., Broch, L., Buysse, D., Dorsey, C., \& Sateia, M. (2008). Clinical guideline for the evaluation and management of chronic insomnia in adults. J Clin Sleep Med, 4, 487-504.

Walsh, J. K., Vogel, G. W., Scharf, M. et al. (2000). A five week, polysomnographic assessment of zaleplon $10 \mathrm{mg}$ for the treatment of primary insomnia. Sleep Med, 1, 41-49. https://doi.org/10.1016/S1389-9457(99)00006-4

\section{Copyrights}

Copyright for this article is retained by the author(s), with first publication rights granted to the journal.

This is an open-access article distributed under the terms and conditions of the Creative Commons Attribution license (http://creativecommons.org/licenses/by/4.0/). 